\title{
Correction to: Signal Detection in Cognitive Radio Networks over AWGN and Fading Channels
}

\author{
Vilaskumar M. Patil ${ }^{1}$ - Rohitha Ujjinimatad ${ }^{2}$ · Siddarama R. Patil ${ }^{1}$
}

Published online: 4 December 2017

๑) Springer Science+Business Media, LLC, part of Springer Nature 2017

\section{Correction to: Int J Wireless Inf Networks https://doi.org/10.1007/s10776-017-0376-x}

The original version of this article unfortunately contained an error in citation. Equation number 24 is incorrectly cited in "Rician Fading Channel" section (Section 3.2) as 25.
The corrected text is given below:

With aid of [22, 6.614-3], the terms C and D of (24) are simplified to.

The original article can be found online at https://doi. org/10.1007/s10776-017-0376-x.

Vilaskumar M. Patil

mpvilaskumar@gmail.com

Rohitha Ujjinimatad

rohitha_ujjini@rediffmail.com

Siddarama R. Patil

pdapatil@gmail.com

1 Department of Electronics and Communication Engineering, Poojya Doddappa Appa (PDA) College of Engineering,

Kalaburagi, India

2 Department of Electronics and Communications,

Proudadevaraya Institute of Technology (PDIT), Hosapete, India 